\title{
Transcriptomic Analysis of Rice Plants Overexpressing PsGAPDH in Response to Salinity Stress
}

\author{
Hyemin Lim ${ }^{1,+}{ }^{,}$Hyunju Hwang ${ }^{2,+}$, Taelim Kim ${ }^{1,+}$, Soyoung Kim ${ }^{3}$, Hoyong Chung ${ }^{4} \oplus$, Daewoo Lee ${ }^{5}$, \\ Soorin Kim ${ }^{6}{ }^{\circ}$, Soochul Park ${ }^{3}$, Woosuk Cho ${ }^{3}$, Hyeonso Ji ${ }^{3,+}$ and Gangseob Lee ${ }^{3, *}$ \\ 1 Department of Forest Bioresources, National Institute of Forest Science, Suwon 16631, Korea; \\ supia1125@korea.kr (H.L.); ktlmi01@korea.kr (T.K.) \\ 2 Department of Applied Marine Bioresource Science, National Marine Biodiversity Institute of Korea, \\ Seocheon 33662, Korea; hjhwang@mabik.re.kr \\ 3 National Institute of Agricultural Science, Rural Development Administration, Jeonju 54874, Korea; \\ sykimflower@korea.kr (S.K.); usdapark@korea.kr (S.P.); phyto@korea.kr (W.C.); jhs77@korea.kr (H.J.) \\ 4 3BIGS CO. LTD., 156 Gwanggyo-ro, Suwon 16429, Korea; hychung@3bigs.com \\ 5 National Institute of Crop Science, Rural Development Administration, Suwon 16430, Korea; dlee@korea.kr \\ 6 School of Food Science \& Biotechnology, Kyungpook National University, Daegu 41566, Korea; \\ soorinkim@knu.ac.kr \\ * Correspondence: kangslee0227@gmail.com \\ + These authors contributed equally to this work.
}

Citation: Lim, H.; Hwang, H.; Kim,

T.; Kim, S.; Chung, H.; Lee, D.; Kim,

S.; Park, S.; Cho, W.; Ji, H.; et al.

Transcriptomic Analysis of Rice Plants Overexpressing PsGAPDH in Response to Salinity Stress. Genes 2021, 12, 641. https://doi.org/ 10.3390/genes12050641

Academic Editor: Yong-Gu Cho

Received: 27 March 2021

Accepted: 22 April 2021

Published: 25 April 2021

Publisher's Note: MDPI stays neutral with regard to jurisdictional claims in published maps and institutional affiliations.

Copyright: (c) 2021 by the authors. Licensee MDPI, Basel, Switzerland. This article is an open access article distributed under the terms and conditions of the Creative Commons Attribution (CC BY) license (https:// creativecommons.org/licenses/by/ $4.0 /)$.
Abstract: In plants, glyceraldehyde-3-phosphate dehydrogenase (GAPDH) is a main enzyme in the glycolytic pathway. It plays an essential role in glycerolipid metabolism and response to various stresses. To examine the function of PsGAPDH (Pleurotus sajor-caju GAPDH) in response to abiotic stress, we generated transgenic rice plants with single-copy/intergenic/homozygous overexpression $P_{S} G A P D H$ (PSGAPDH-OX) and investigated their responses to salinity stress. Seedling growth and germination rates of $P S G A P D H-O X$ were significantly increased under salt stress conditions compared to those of the wild type. To elucidate the role of PsGAPDH-OX in salt stress tolerance of rice, an Illumina HiSeq 2000 platform was used to analyze transcriptome profiles of leaves under salt stress. Analysis results of sequencing data showed that 1124 transcripts were differentially expressed. Using the list of differentially expressed genes (DEGs), functional enrichment analyses of DEGs such as Gene Ontology (GO) terms and Kyoto Encyclopedia of Genes and Genomes (KEGG) pathways were performed. KEGG pathway enrichment analysis revealed that unigenes exhibiting differential expression were involved in starch and sucrose metabolism. Interestingly, trehalose6-phosphate synthase (TPS) genes, of which expression was enhanced by abiotic stress, showed a significant difference in PsGAPDH-OX. Findings of this study suggest that PsGAPDH plays a role in the adaptation of rice plants to salt stress.

Keywords: glyceraldehyde-3-phosphate dehydrogenase; salt stress; tolerance; transcriptomic analysis; transgenic rice

\section{Introduction}

Plants continuously face environmental stressors, including drought, high salinity, and extreme temperatures. These stressors affect both biomasses and grain yields of crops. Salt stress is a particularly important abiotic stress that can seriously affect the development, growth, and productivity of plants. Severe stress may threaten their survival. Rice (Oryza sativa) is a major staple food crop in the world. It is also a model plant for the genomics research of monocotyledons [1]. Salinity is one of the most disastrous abiotic stresses for rice. Salt-affected soils currently account for approximately $20 \%$ of global agricultural production [2]. Recently, many studies have reported molecular and cellular mechanisms such as ERF1, OsMYB91, and OsGLYII-2 involved in the tolerance of rice to 
salt [3-5]. It is well known that rice is extremely sensitive to salt stress. Thus, more genes might be involved in its salt resistance.

Glyceraldehyde-3-phosphate dehydrogenase (EC 1.2.2.12) (GAPDH) is a glycolytic enzyme that catalyzes the oxidation of triose phosphates during glycolysis in all organisms. GAPDH plays multiple roles in the regulation of autophagy, hypersensitive response, and plant immune responses [6-8]. In addition, the phosphorylation of NAD-GAPDH and comprehensive analysis of the GAPDH gene family in wheat were conducted $[9,10]$. GAPDH is an important enzyme in two metabolism pathways for sugar: glycolysis and gluconeogenesis. In plants, glycolysis is the predominant respiratory pathway that provides ATP, reductants, and precursors for plant growth and development [11]. Glycolysis is also involved in the adaptation of plants to stress conditions such as salt, cold, drought, and anoxia [12-14]. What is especially noteworthy is that salt stress tolerance can lead to the expression of GAPDH genes at the transcription level in fungi such as Aspergillus nidulans [15]. Based on this, we have isolated a GAPDH gene from the oyster mushroom, Pleurotus sajorcaju (PsGAPDH), and characterized its expression under various abiotic stresses basis in a previous study [16]. Potato overexpressing PsGAPDH also shows increased salt tolerance [17]. However, no comprehensive physiological explanation has been provided. It is known that overexpression of genes in transgenic plants can improve plant resistance to various abiotic stresses [18]. In a previous study, we have generated transgenic rice plants overexpressing PsGAPDH [19]. To investigate the mechanism of PsGAPDH in salinity stress, transcriptome analysis was performed.

Lately, next-generation sequencing (NGS) technology has been advancing rapidly. It provides a fast, cost-effective, and comprehensive analysis of complex nucleic acid groups of model plants (or closely related species) and non-model plants [20,21]. Next-generation high-throughput RNA sequencing technology could overcome shortcomings of arraybased technologies. With high resolution and sensitivity, RNA sequencing can be used to discover new splice junctions, new transcripts, alternative transcription start sites, and rare transcripts [22]. Additionally, RNA sequencing data show a high level of reproducibility in both technical and biological replications [23]. To date, global gene expression profiles of organisms including plants have been obtained by RNA sequencing [24-27]. Moreover, RNA sequencing has been widely used in comparative transcriptomics to recognize differences in transcript abundance among different cultivars, organs, and treatment conditions [28]. To identify genes exhibiting transcriptional changes, we compared transcriptomes of saltstressed and control rice plants and analyzed their functions and KEGG pathways.

In this study, we used RNA sequencing to analyze transcriptomes of wild-type and PsGAPDH-overexpressing rice plants under salinity stress to obtain detailed expression profiles of genes involved in salt stress response. Assembled and annotated transcriptome sequences and their transcription abundance patterns will provide a valuable genetic resource to further investigate molecular mechanisms involved in the salt tolerance of rice. In particular, among candidates for this genetic resource, the TPS genes showed a significant difference in expression in PSGAPDH-OX. OsTPS1 has been reported to increase the expression by abiotic stress and enhance the expression of stress-related genes [29]. These results suggested that PsGAPDH may play a role in tolerance mechanisms of salinity stress.

\section{Materials and Methods}

\subsection{Plant Materials and Generation of Transgenic Rice}

Rice (Oryza sativa L. cv. Dongjin) was used in this study. Sterilized seeds were germinated on MS medium in a growth chamber equipped with fluorescent lamps $\left(28^{\circ} \mathrm{C}\right.$, $16 \mathrm{~h}$ light $/ 8 \mathrm{~h}$ dark cycle, $300 \mu \mathrm{mol} \mathrm{m}{ }^{-2} \mathrm{~s}^{-1}$ ). Dongjin seeds were used to produce PsGAPDH-overexpressing rice plants. Rice seeds were sterilized with $70 \%$ ethanol and $2 \%$ $\mathrm{NaClO}$. All tissue samples collected were immediately frozen in liquid nitrogen and stored at $-70{ }^{\circ} \mathrm{C}$. 
To construct an overexpression vector, full-length cDNA of PsGAPDH was cloned into a plant expression vector PPZP, which was constructed by introducing CaMV35S promoter and PinII terminator containing Bar as a plant selectable marker (Figure 1A) [19,30]. The 35S::PsGAPDH construct was introduced into an Agrobacterium tumefaciens strain LB4404 to generate transgenic rice [19]. Rice plants were transformed by Agrobacterium infection as described previously [31]. Transgenic rice plants were regenerated from transformed calli on selection medium containing $4 \mathrm{mg} / \mathrm{L}$ phosphinothricin and $500 \mathrm{mg} / \mathrm{L}$ cefotaxime and subsequently grown in a greenhouse.

A

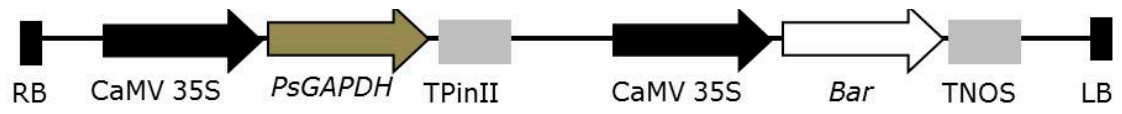

\section{$35 S: \because P S G A P D H$}

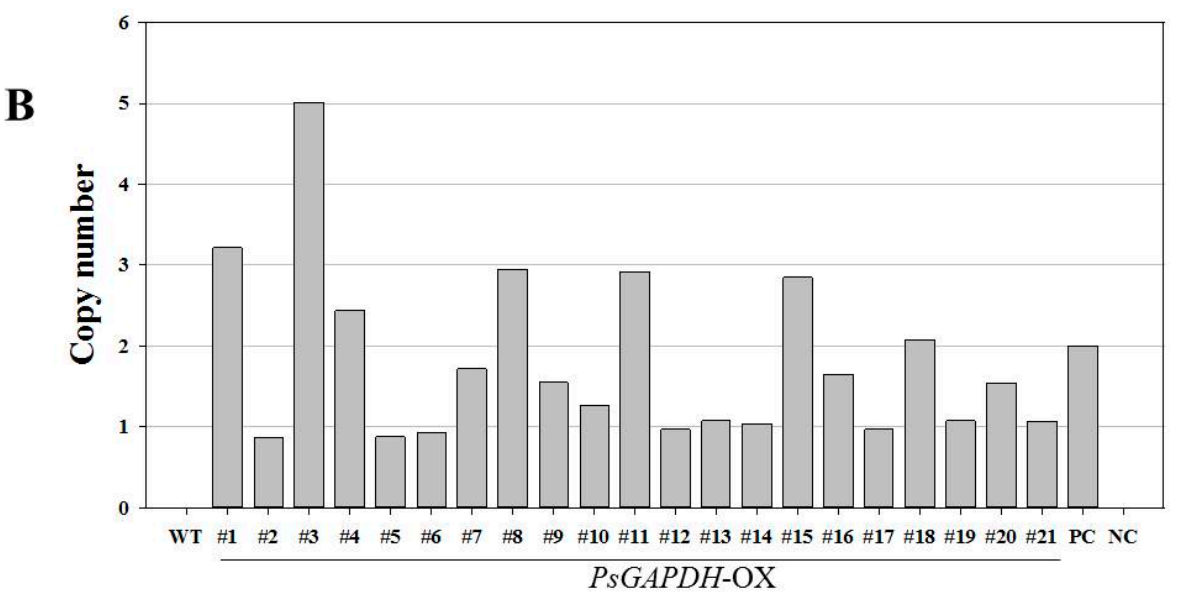

C

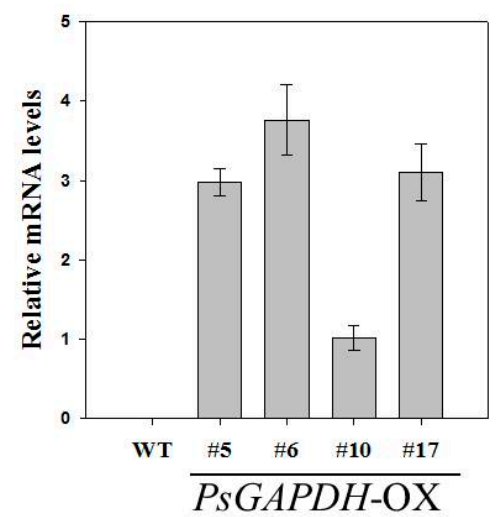

D

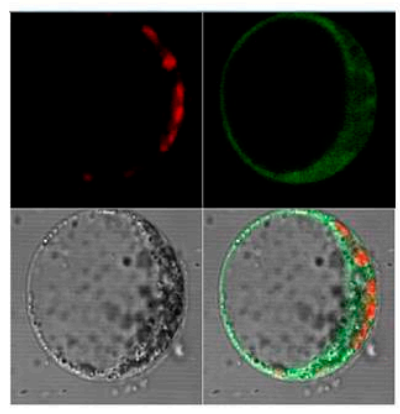

Maize protoplast

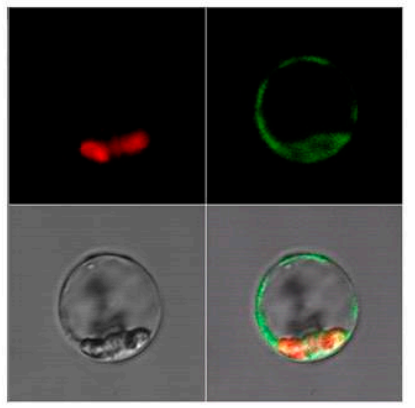

Arabidopsis protoplast

Figure 1. Generation of transgenic rice plants overexpressing PSGAPDH. (A) Schematic diagram of a plant expression vector pPZP-PSGAPDH used for overexpressing $P_{S} G A P D H$ in transgenic rice. (B) TaqMan copy number analysis of $P s G A P D H$ transgenic plants for transgene copy determination. (C) Expression levels of PsGAPDH in transgenic plants by quantitative real time-PCR. Three transgenic lines (\#5, \#6, and \#17) displayed high PsGAPDH expression compared to \#10 plant. (D) Subcellular localization of PsGAPDH. Fluorescence signals in maize and Arabidopsis protoplasts were visualized using a confocal laser-scanning microscope. \#, number; RB,T-DNA right border; LB, T-DNA left border; WT, wild type; PC, positive control; NC, negative control.

\subsection{Genomic DNA Extraction and TaqMan Copy Number Analysis}

Genomic DNA of transgenic plants was extracted using an IncloneTM Genomic DNA Prep Kit (Inclone, Korea). Copy number assay was performed on an Applied Biosystems StepOnePlusTM (Applied Biosystems, Foster City, CA, USA) with a TaqMan ${ }^{\circledR}$ Gene Expression Master Mix (Applied Biosystems) kit. Primers and probes of the predesigned TaqMan ${ }^{\circledR}$ copy number assay for rice tubulin $\alpha-1$ chain gene (AK102560) as an 
endogenous control were used. For the transgene, primers and probes were specifically designed for the terminator of the nos gene. Gene-specific primers used were NOS-F 5'GCATGACGTTATTTATGAGATGGGTTT-3' ${ }^{\prime}$ and NOS-R $5^{\prime}$-TGCGCGCTA TATTTTGTTTTCTATCG-3'. NOS-probe 5'-TAGAGTCCCGCA ATTAT-3' was also used for the nos gene. PCR conditions were as follows: $10 \mathrm{~min}$ at $95^{\circ} \mathrm{C}$; followed by 40 cycles of $95^{\circ} \mathrm{C}$ for $15 \mathrm{~s}, 60^{\circ} \mathrm{C}$ for $1 \mathrm{~min}$, and $72{ }^{\circ} \mathrm{C}$ for $1 \mathrm{~min}$. In the reaction plate, each sample was measured in triplicate. To calculate the copy number of a target gene, relative quantitation analysis of genomic DNA target was analyzed based on real-time PCR data using Applied Biosystems CopyCaller ${ }^{\circledR}$ Software v2.0 (Applied Biosystems) according to the manufacturer's instructions.

\subsection{Transient Expression Analysis in Protoplast}

The cDNA sequence of $P S G A P D H$ was cloned with a GFP fusion protein (PsGAPDH: GFP) into a pJJ2485-GFP expression vector using a gateway recombination system (Invitrogen, Life technologies, Carlsbad, CA, USA). Protoplast transformation was performed as previously described [32]. Transformed protoplasts were observed with a confocal microscope (LSM 510 META, Carl Zeiss, Jena, Germany). Autofluorescence of chlorophyll was used as a chloroplast marker.

\subsection{Salt Stress Treatment}

Salt stress treatment for transgenic rice plants was performed using a published method [33]. For the phenotypic analysis of PSGAPDH-OX plants in response to salt stress, sterilized rice seeds were transferred into 1/2 Murashige and 1/2 MS medium containing $100 \mathrm{mM} \mathrm{NaCl}$ or $1 / 2 \mathrm{MS}$ liquid medium containing $200 \mathrm{mM} \mathrm{NaCl}$. Seeds were incubated at $28{ }^{\circ} \mathrm{C}$ for 5 days or 14 days. Germination and seedling growth of transgenic plants and wild-type seeds sown on MS agar plates at each nutrient level was monitored. Three replicates with 15 seeds in each replicate were used. All data were analyzed by $t$-tests. Significant differences are indicated by asterisks $\left({ }^{*}, p<0.05 ;{ }^{* *}, p<0.01\right)$. All the data from control and treatments were subjected to statistical analysis using SPSS 20.0.

For RNA sequence analysis of PsGAPDH-OX in response to salt stress, two-week-old seedlings were transferred to soil culture in a greenhouse. After 7 weeks, all plants were subjected to treatment with $200 \mathrm{mM} \mathrm{NaCl}$ (salt stress) for 3 days. RNA sequence analyses of three biological replicates for each wild-type and transgenic plants were then performed.

\subsection{RNA Extraction, cDNA Library Construction, and Sequencing}

Total RNAs were extracted from rice leaves using an RNeasy ${ }^{\circledR}$ Plant mini kit (QIAGEN, Hilden, Germany) according to the manufacturer's protocol. RNA quality was determined with a 2100 Bioanalyzer (Agilent, Santa Clara, CA, USA). Only samples with an RNA integrity number $>8$ were used for library preparation. Each paired-end cDNA library was constructed using a TruSeq RNA Sample Preparation Kit (Illumina, San Diego, CA, USA).

\subsection{Pre-Processing of RNA Sequencing Data}

Based on RNA libraries generated, paired-end sequencing was performed using a Hiseq2000 platform (Illumina). To generate clean reads, Trimmomatic (ver 0.36; [34]) was used. Per-base sequence qualities were checked using FastQC (ver. 0.11.2) (http:/ / www. bioinformatics.babraham.ac.uk/projects / fastqc/ accessed on 26 March 2021). Fastq files were then filtered. Trimmed reads were aligned to a reference genome (Oryza_sativa.IRGSP1.0) using HISAT software version 2-2.1.0 [35]. To compare reads containing the strand information to those without, reads were also aligned without using the '-RNA-strandness $\mathrm{RF}^{\prime}$ option. We quantified mapped reads using FeatureCounts with annotation files (.GFF3) for protein-coding genes [36].

\subsection{Differential Expressed Gene (DEG) Analysis}

Differentially expressed genes (DEGs) were identified using an edgeR Bioconductor package based on a Generalized Linear Model (GLM) used for RNA-seq data analysis, 
considering gene expression as a negative binomial [37]. The EdgeR-robust method [38] was used to reduce the effect of outlier genes. Based on quantified gene expression, relationships among samples and stages were investigated using a multidimensional scaling (MDS) method. A heatmap was generated to visualize DEGs which included the 500 most expressed genes (TMM upper value) across samples using R. A volcano plot was obtained to visualize differential expression between samples. Significant differences (Log-fold change $>2.0$ or Log-fold change $<-2.0, p$-value $<0.05$ ) between two different conditions were illustrated in the volcano plot. All identified proteins were annotated with the Os-Nipponbare-Reference-IRGSP-1.0 database (https:/ / rapdb.dna.affrc.go.jp accessed on 26 March 2021). An adjusted $p$-value (FDR) $<0.05$ was used as the significance cutoff for differentially expressed genes.

\subsection{Gene Ontology (GO) and Kyoto Encyclopedia of Genes and Genomes (KEGG) Pathway Analysis}

DEGs were further processed with DAVID 6.8 Functional Annotation Tool (http: / / david.abcc.ncifcrf.gov / accessed on 26 March 2021) for term enrichment analysis [39]. Results were filtered using a Fisher's exact statistic methodology as previously described [39].

\subsection{Quantitative Real-Time PCR ( $q$ RT-PCR)}

Transcriptome sequencing data were validated by qRT-PCR. Briefly, RNAs $(1 \mu \mathrm{g})$ were reverse-transcribed to cDNAs using an AmfiRevert cDNA synthesis kit (Gendepot, USA). Synthesized cDNAs were used as templates for qRT-PCR. Primer pairs specific for the amplification of target genes are shown in Supplementary Table S4. Relative quantification was performed to calculate expression levels of target genes in different treatments using the $2^{-\Delta \Delta \mathrm{Ct}}$ method. The expression level of OsActin1 was used for the normalization of real-time PCR results. All data are expressed as the mean \pm SD from three independent experiments.

\section{Results}

\subsection{Generation of Rice Plants Overexpressing PsGAPDH}

The PsGAPDH gene from Pleurotus sajor-caju (Oyster mushroom) is highly induced by salt, drought, cold, and heat stress conditions [16,17]. Interestingly, it has been reported that transgenic potato plants constitutively expressing the $P_{S} G A P D H$ gene can increase their salt tolerance under salt stress conditions [17]. Thus, rice plants overexpressing PsGAPDH (PSGAPDH-OX) were generated by introducing a construct containing the fulllength cDNA of PsGAPDH under the control of a CaMV35S promoter (Figure 1A). A total of $149 \mathrm{~T} 0$ generation lines of PsGAPDH-OX rice plants were generated. TaqMan copy number assay was used to select single-copy lines from PsGAPDH-OX plants (Figure 1B). Flanking sequence tag (FST) analysis of T0 plants was carried out only for those transgenic plants in which a single copy T-DNA insertion was confirmed. Transgenic plants with the T-DNA inserted in an intergenic region are less likely to be affected by other genes. Hence, single copy/intergenic transgenic plants were selected using FST analysis (Supplementary Table S1) [19]. We obtained five single copy/intergenic transgenic plants from 21 lines of transformants. PsGAPDH-OX (\#5, \#6, \#10, and \#17) plants with a singlecopy and an intergenic insertion were selected and separated to produce homozygous T3 generation. Transcriptional levels of the PsGAPDH gene in these four lines of singlecopy/intergenic/homozygous $P_{S} G A P D H$-OX plants were determined using qRT-PCR. Results of qRT-PCR revealed that $P_{S} G A P D H$ was overexpressed in transgenic rice plants. PsGAPDH-OX \#10 line showed a relatively low level of expression compared to other transgenic rice lines (Figure 1C). Single-copy/intergenic/homozygous PsGAPDH-OX (\#5, $\# 6$, and \#17) plants were then selected and used in subsequent experiments. 


\subsection{Subcellular Localization of PsGAPDH}

GAPDH catalyzes the conversion of glyceraldehyde-3-phosphate to 1,3-bisphospho glycerate. Both cytosolic (GAPCs) and plastidial (GAPCps) GAPDH activities have been described in plants. To determine the subcellular localization of PsGAPDH expression, the distribution of $P_{S} G A P D H$ in maize and Arabidopsis protoplasts was examined. PsGAPDH-GFP proteins were transiently expressed in protoplasts isolated from leaves using a polyethylene glycol (PEG)-mediated transfection system [32]. A fusion protein with GFP was expressed and its localization was visualized using a laser scanning confocal microscope. As shown in Figure 1D, PsGAPDH-GFP was predominantly present in the cytoplasm of Arabidopsis and maize. This result demonstrates that PsGAPDH is protein-localized in the cytoplasm.

\subsection{Effect of PsGAPDH-OX on Seedling Growth under Salt Stress Condition}

To assess the role of PsGAPDH in the salt stress response of rice, seeds of PsGAPDH$\mathrm{OX}$ and wild-type rice were sown on MS agar plates containing different concentrations $(100 \mathrm{mM}$ and $200 \mathrm{mM})$ of $\mathrm{NaCl}$. Their germination rates and seedling growths were monitored. There was no significant difference between the wild-type and PsGAPDH-OX cultured in MS medium without $\mathrm{NaCl}$ (Figure 2). However, when they were cultured in MS medium containing $100 \mathrm{mM}$ or $200 \mathrm{mM} \mathrm{NaCl}$ for 8 days, PsGAPDH-OX \#5, \#6, and \#17 rice lines showed different germination rates from that of the wild-type. In MS medium containing $100 \mathrm{mM} \mathrm{NaCl}$, the germination rate of wild-type rice seeds was $68 \%$, while those of PsGAPDH-OX \#5, \#6, and \#17 were 95\%, 76\%, and 85\%, respectively (Figure 2). In MS medium containing $200 \mathrm{mM} \mathrm{NaCl}$, the germination rate of the wild-type rice seed was $49 \%$, while those of PsGAPDH-OX \#5, \#6, and \#17 were $60 \%, 67 \%$, and $49 \%$, respectively. After 14 days of culturing, PsGAPDH-OX \#6 seedlings showed significantly better growth performance than the wild-type $(p<0.05)$ on MS media supplemented with $100 \mathrm{mM}$ or $200 \mathrm{mM} \mathrm{NaCl}$ (Figure 3). These results suggested that PsGAPDH-OX lines were resistant to salt stress.

$\mathbf{A}$

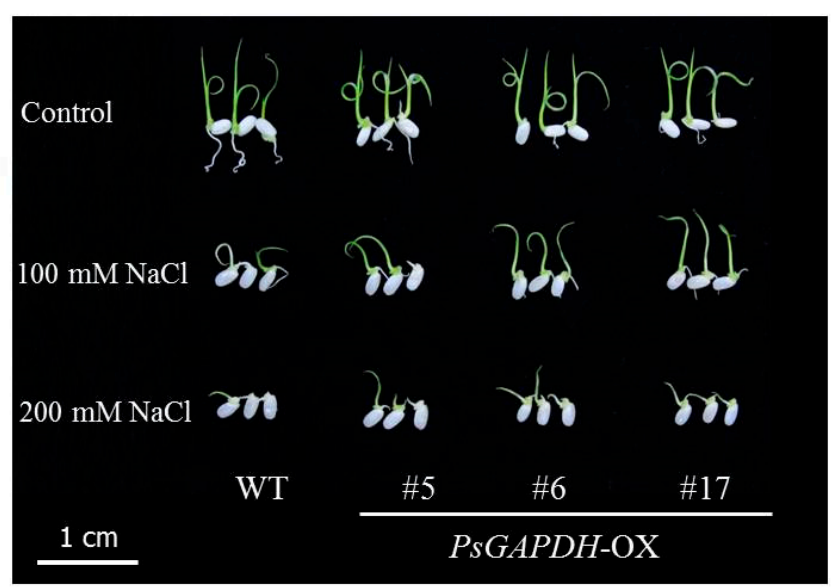

\section{B}

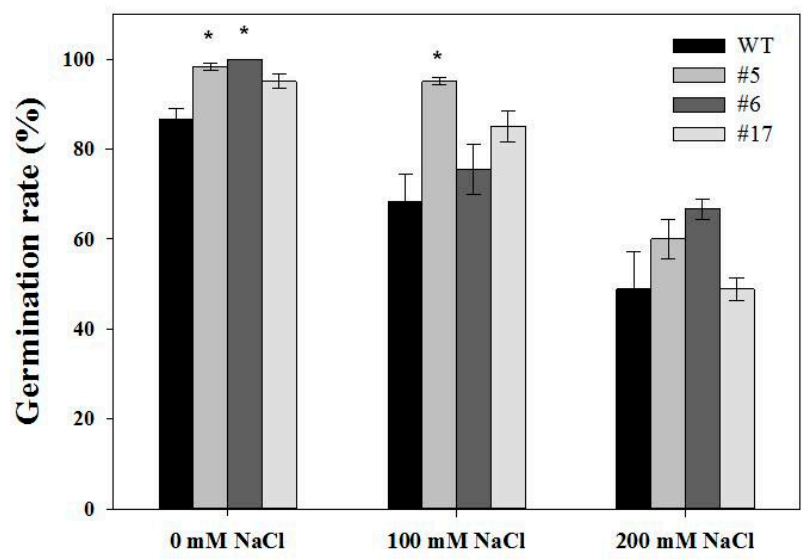

Figure 2. Seed germination rate of $P S G A P D H-O X$ transgenic plants under salt stress. (A) Seed germination phenotypes of wild-type (Control) and PsGAPDH-OX plants treated with $100 \mathrm{mM}$ or $200 \mathrm{mM} \mathrm{NaCl}$ for 5 days. (B) Graph of germination rates. For each treatment, 15 seeds were measured. Error bar represents the SD of three replicates. Significant differences depending on $t$-tests are indicated by asterisks $\left({ }^{*}, p<0.05\right)$. 
A

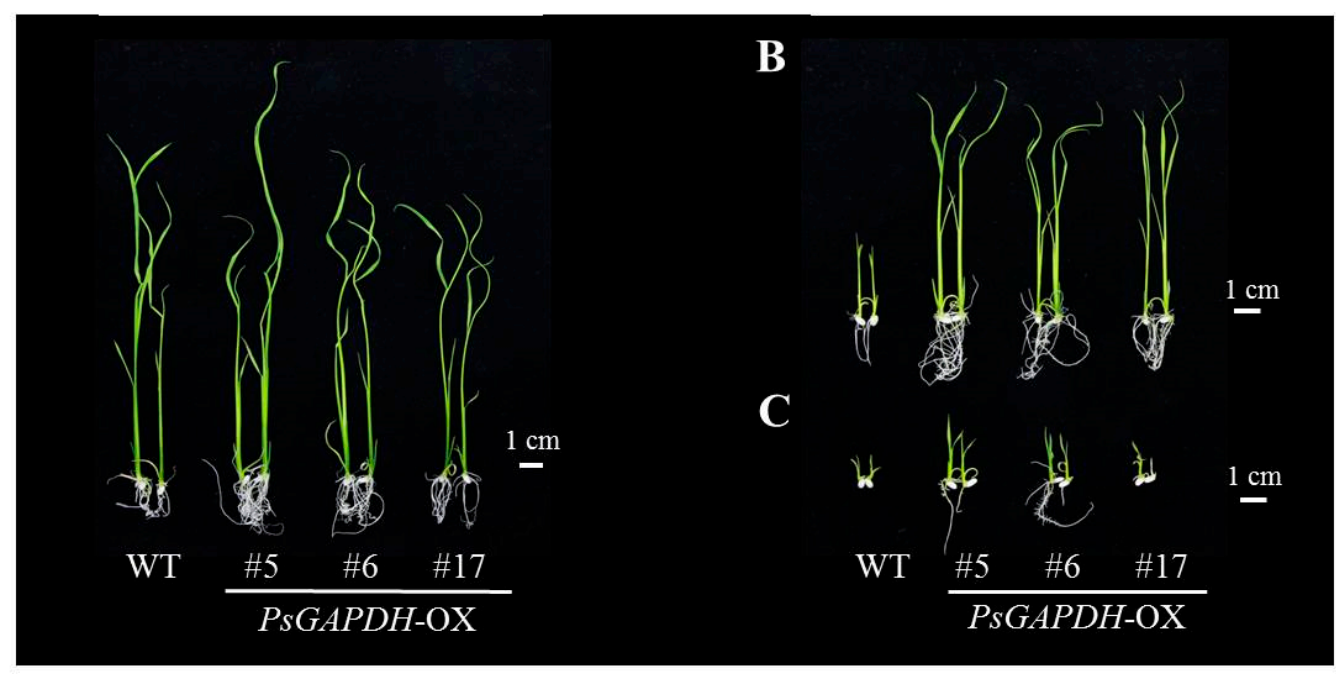

D

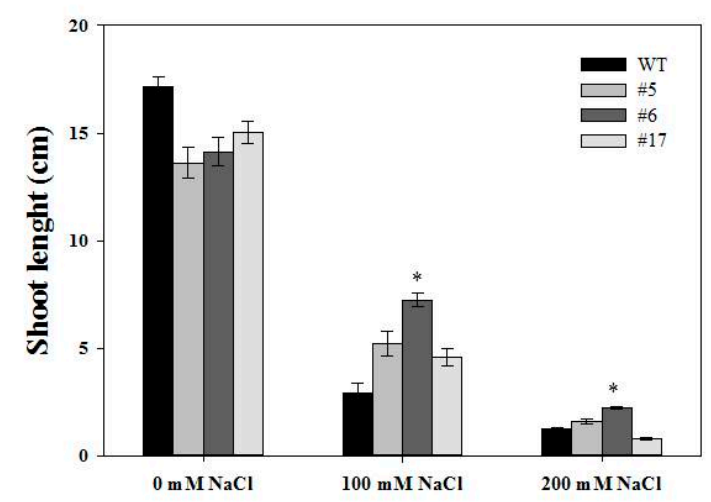

$\mathbf{E}$

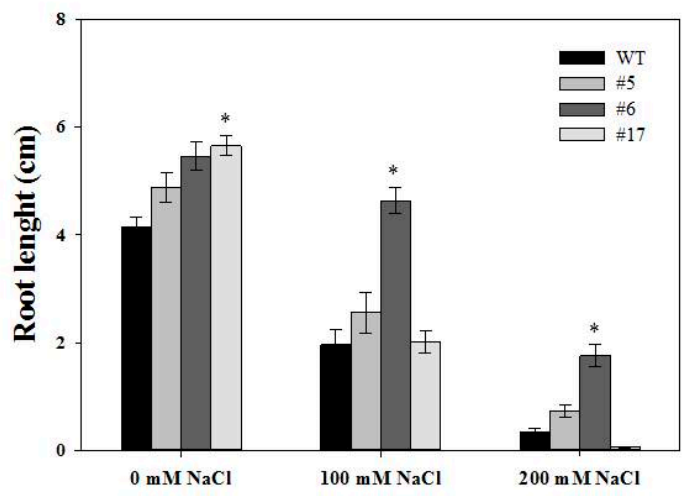

Figure 3. Phenotypic comparison of PSGAPDH-OX transgenic plants under salt stress. Phenotypes of wild-type and PsGAPDH-OX rice plants grown on MS medium containing $0 \mathrm{mM}$ (A), $100 \mathrm{mM}$ (B), and $200 \mathrm{mM}$ (C) $\mathrm{NaCl}$ for 2 weeks. Effect of 2 weeks of salt stress on shoot (D) and root (E) lengths of PsGAPDH-OX plants. For each treatment, 15 seedlings were measured. Error bar represents the SE of three replicates. Significant differences depending on $t$-tests are indicated by asterisks $\left({ }^{*}, p<0.05\right)$.

\subsection{Statistical Test for DEG}

Based on quantified gene expression, relationships among samples and stages were investigated using the MDS method. Multi-dimensional plot indicated that samples could be distinguished by transgenic rice (Figure 4). After checking distances of samples, statistical tests were performed to identify DEGs between control and transgenic samples. Total 1124 genes expressed significant differences that up-regulated and down-regulated genes were 603 and 521, respectively (Figure 5).

The top 10 down-regulated DEGs and top 10 up-regulated DEGs matched with Oryzabase gene symbols and Oryzabase gene name synonym(s) with an adjusted $p$-value $<0.05$ (Table 1). Typically, many F-box protein genes were up- or down-regulated. A total of 396 F-box genes were included in 1124 DEGs (Supplementary Table S3). The heatmap of the 500 most expressed genes (TMM upper value) across samples showed that control samples were clustered with each other (Figure 6). A total of 1124 DEGs were selected based on a significance cutoff of FDR $<0.05$. 

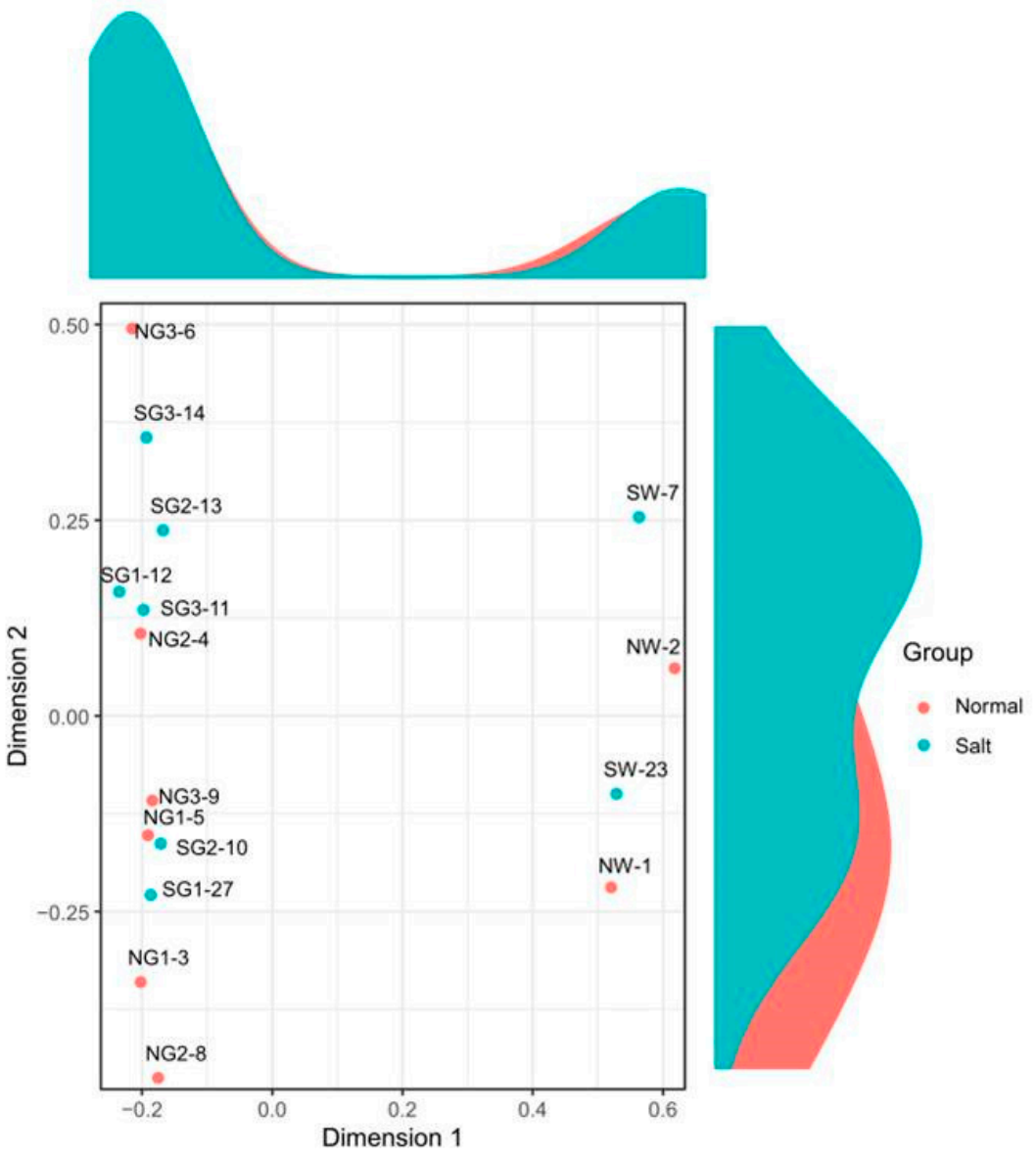

Figure 4. Multi-dimensional scaling (MDS) plot based on the transcriptomic analysis of wild-type rice plants and transgenic rice plants overexpressing $P_{S} G A P D H$. Each point represents an RNA-seq sample. "Normal" and "Salt" groups are illustrated.

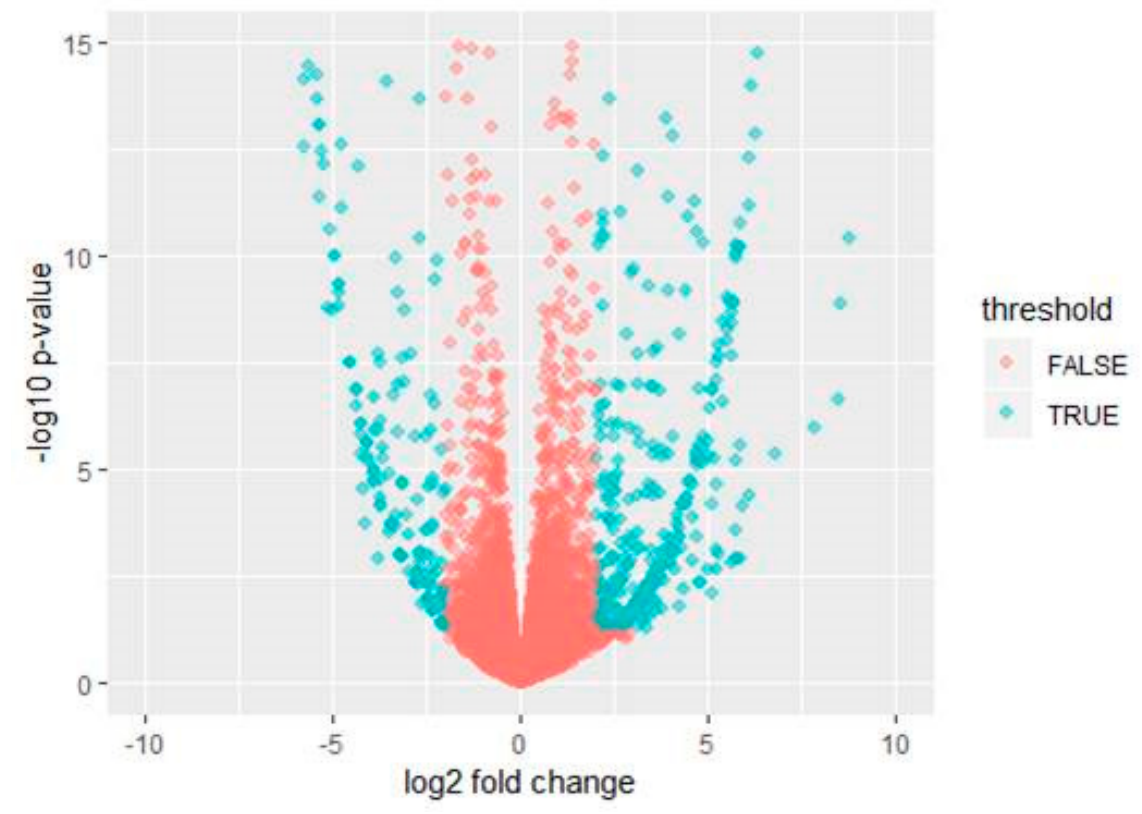

Figure 5. Expression changes of all genes. The volcano map displays expression changes of all genes. Blue represents differentially expressed genes (Log-fold change $>2.0$ or Log-fold change $<-2.0$, $p$-value $<0.05)$ between Normal and PsGAPDH transgenic samples. 
Table 1. Log-fold changes of top 10 down-regulated DEGs and top 10 up-regulated DEGs in Normal sample vs. PsGAPDH transgenic sample. Table 1 contains top 10 down-regulated DEGs and top 10 up-regulated DEGS with an adjusted $p$-value $<0.05$.

\begin{tabular}{|c|c|c|c|c|}
\hline Genes & Gene Symbol & Gene Name & $\log \mathrm{FC}$ & FDR \\
\hline \multicolumn{5}{|l|}{$\operatorname{LogFC}<0$} \\
\hline Os11t0532600-01 & OsFbox601 & F-box protein 601 & -8.756393 & $1.61 \times 10^{-147}$ \\
\hline Os10t0138100-01 & $\mathrm{AO}$ & aldehyde oxidase & -8.680868609 & $3.26 \times 10^{-90}$ \\
\hline Os12t0247700-01 & OsJAC1, JAC1 & jacalin-related lectin 1 & -5.864641 & $1.82 \times 10^{-17}$ \\
\hline Os11t0691800-01 & OsRLCK354 & $\begin{array}{c}\text { Receptor-like Cytoplasmic } \\
\text { Kinase } 354\end{array}$ & -5.791724 & $1.03 \times 10^{-12}$ \\
\hline Os11t0615800-01 & OsRAD51A1 & DNA repair protein RAD51A1 & -5.684418 & $5.72 \times 10^{-23}$ \\
\hline Os07t0535100-01 & OsFbox375 & F-box protein 375 & -5.682947 & $1.10 \times 10^{-14}$ \\
\hline Os12t0420000-00 & OsSTA280 & & -5.490965 & $2.02 \times 10^{-80}$ \\
\hline Os12t0221600-01 & OsRALF-35 & Rapid alkalization factor 35 & -5.368038 & $1.10 \times 10^{-11}$ \\
\hline Os11t0685700-00 & OsWRKY61 & Rice WRKY gene61 & -5.264582 & $8.04 \times 10^{-69}$ \\
\hline Os01t0824700-01 & OsFbox048 & F-box protein 48 & -4.959153931 & $5.93 \times 10^{-72}$ \\
\hline $\begin{array}{c}\operatorname{LogFC}>\mathbf{0} \\
\text { Os12t0121600-01 }\end{array}$ & OsCHX09 & cation/H+ exchanger 9 & 7.468688 & $2.79 \times 10^{-21}$ \\
\hline Os02t0825500-01 & OsFbox123 & F-box protein 123 & 7.421409 & $1.78 \times 10^{-24}$ \\
\hline Os02t0771600-01 & OsACO3 & ACC oxidase 3 & 7.030725 & $1.27 \times 10^{-43}$ \\
\hline Os07t0158900-01 & OsFbox341 & F-box protein 341 & 6.116181 & $7.87 \times 10^{-46}$ \\
\hline Os06t0286700-00 & Piz(Pi2, Pi-z, Piz) & $\begin{array}{l}\text { Pyricularia oryzae resistance-z, } \\
\text { Magnaporthe grisea resistance-z }\end{array}$ & 4.353849 & $1.65 \times 10^{-27}$ \\
\hline Os12t0601400-01 & OsIAA3 & $\begin{array}{l}\text { Aux/IAA protein } 3, \text { Aux/IAA } \\
\text { protein } 31\end{array}$ & 3.131579 & $1.36 \times 10^{-16}$ \\
\hline Os12t0577700-00 & Orysa; CKL1 & $\begin{array}{l}\text { CDK-LIKE 1, cyclin-dependent } \\
\text { kinase-like } 1\end{array}$ & 2.877962 & $3.72 \times 10^{-26}$ \\
\hline Os11t0533800-01 & OsFbox602 & F-box protein 602 & 2.200298 & $4.17 \times 10^{-30}$ \\
\hline Os10t0136500-01 & & receptor-like kinase & 2.18271271 & $2.30 \times 10^{-16}$ \\
\hline Os10t0437100-01 & OsCAT7 & cationic amino acid transporter 7 & 1.511570768 & $2.80 \times 10^{-17}$ \\
\hline
\end{tabular}

\subsection{GO and KEGG PATHWAY Analysis}

Using the list of 1124 DEGs, functional enrichment of DEGs such as GO terms and the KEGG pathway were investigated (Table 2). In KEGG pathways of DEGs, metabolism of starch and sucrose was significantly enriched (Figure 7). Trehalose-6-phosphate (T6P), an intermediate of trehalose biosynthesis, is an essential signal metabolite in plants. It is linked to growth and development according to carbon status. In this study, the trehalose-6phosphate synthase (TPS) gene for transferring Gluc-6P to T6P was down-regulated, whereas the trehalose-6-phosphate phosphatase (TPP) gene for transferring T6P to trehalose was upregulated (Table 3). After TPS converts glucose-6-phosphate and UDP-glucose into T6P, T6P is then dephosphorylated into trehalose by TPP. 


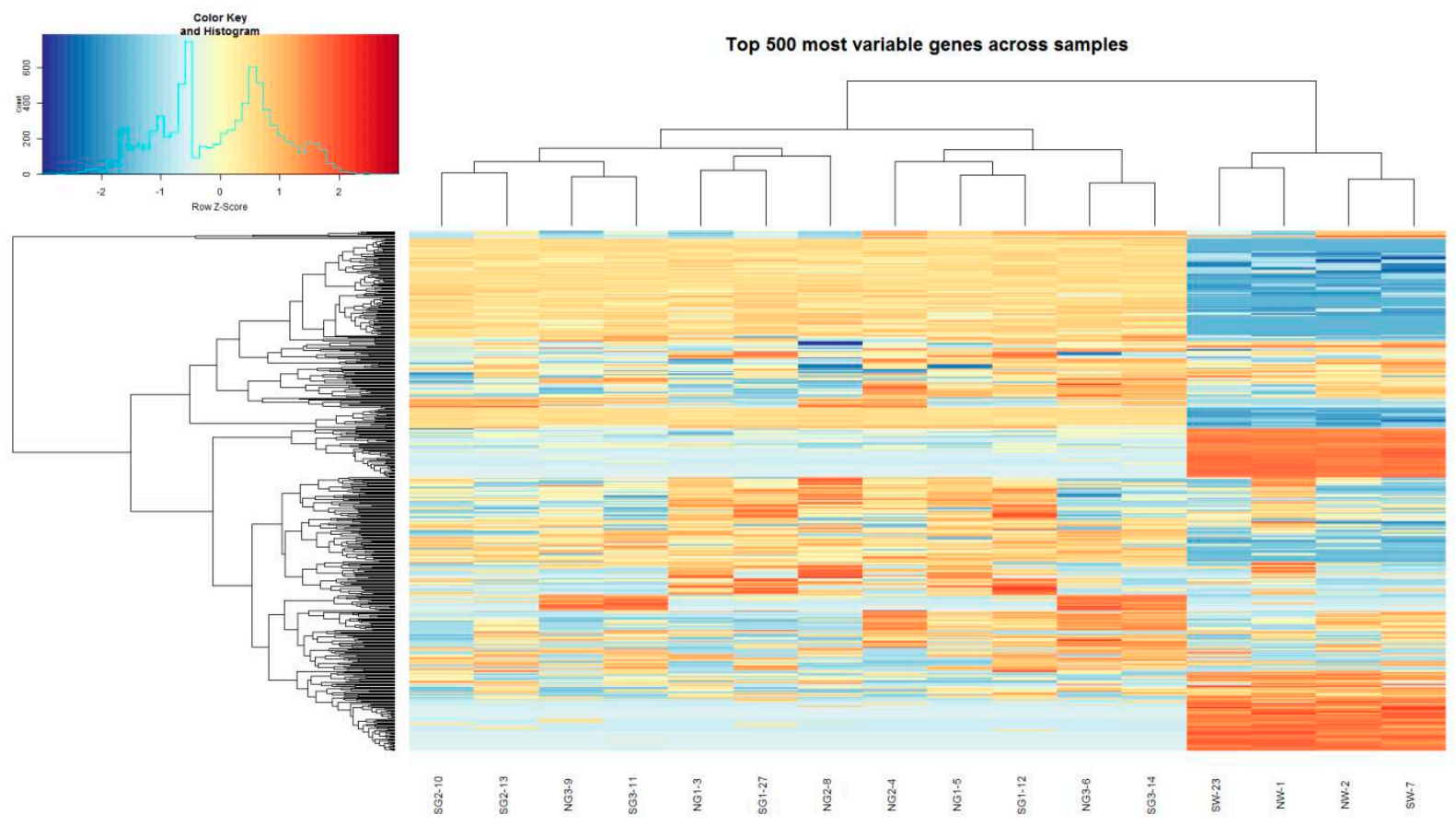

Figure 6. Expression patterns of the most significantly expressed genes across total samples. In the heatmap, the color indicates the expression level of a gene and the column header indicates a sample.

Table 2. Functional classification of differentially expressed proteins in rice samples. Proteins are classified into three main categories by GO analysis: biological process, cellular component, and molecular function. Column headers indicate the number of genes in a category, the percentage of a specific category of genes in that category, and the name of genes in that category. KEGG analysis showed one metabolism category. Results were filtered with a $p$-value $<0.05$ as a cutoff.

\begin{tabular}{|c|c|c|c|c|}
\hline GO Term & Count & Percent of Proteins & $p$-Value & Genes \\
\hline \multicolumn{5}{|l|}{ Biological Process } \\
\hline $\begin{array}{l}\text { GO:0051365 cellular response to } \\
\text { potassium ion starvation }\end{array}$ & 2 & $4.57 \%$ & 0.015 & CIPK9, SS2 \\
\hline GO:0010555 response to mannitol & 2 & $4.57 \%$ & 0.017 & CIPK9, SUS1 \\
\hline GO:0030154 cell differentiation & 4 & $9.15 \%$ & 0.020 & FT, PI, MYB61, MYB55 \\
\hline $\begin{array}{c}\text { GO:0055062 phosphate ion } \\
\text { homeostasis }\end{array}$ & 2 & $4.57 \%$ & 0.027 & CAX1, PHO2 \\
\hline GO:0051026 chiasma assembly & 2 & $4.57 \%$ & 0.031 & MSH4, DMC1 \\
\hline $\begin{array}{l}\text { GO:0009684 indoleacetic acid } \\
\text { biosynthetic process }\end{array}$ & 2 & $4.57 \%$ & 0.033 & NIT1, AMI1 \\
\hline \multicolumn{5}{|l|}{ Cellular Component } \\
\hline GO:0005783 endoplasmic reticulum & 6 & $13.72 \%$ & 0.003 & $\begin{array}{l}\text { FT, SPX2, YUC4, } \\
\text { PDIL1-4, PHO2, } \\
\text { MSRB3 }\end{array}$ \\
\hline \multicolumn{5}{|l|}{ Molecular Function } \\
\hline $\begin{array}{l}\text { GO:0016810 hydrolase activity, } \\
\text { acting on carbon-nitrogen (but not } \\
\text { peptide) bonds }\end{array}$ & 2 & $4.57 \%$ & 0.020 & NIT1, AMI1 \\
\hline KEGG analysis & Count & Percent of Proteins & $p$-Value & Genes \\
\hline $\begin{array}{l}\text { ath00500:Starch and } \\
\text { sucrose metabolism }\end{array}$ & 4 & $9.15 \%$ & 0.007 & DPE2, SS2, TPS3, SUS1 \\
\hline
\end{tabular}




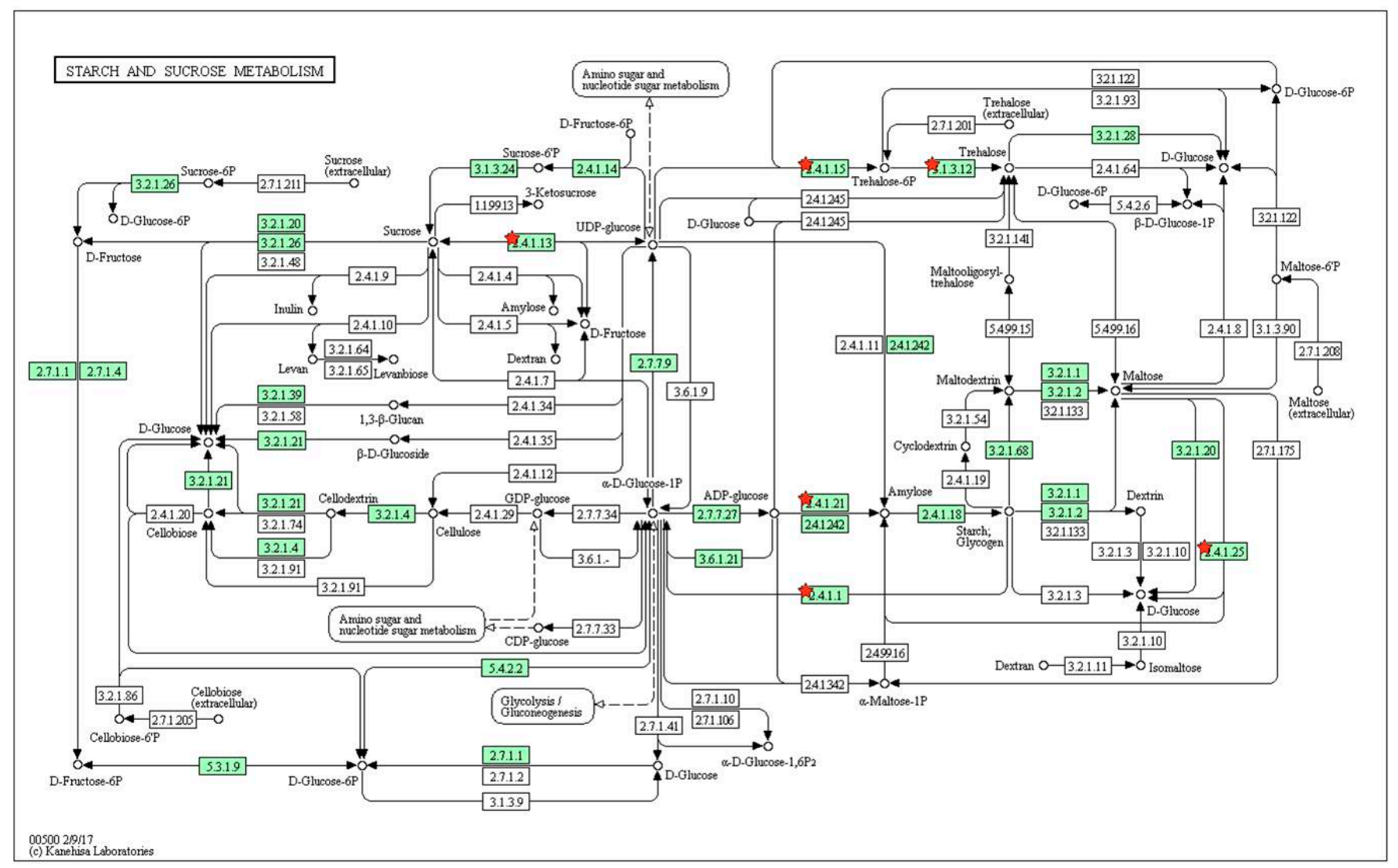

Figure 7. KEGG pathway for starch and sucrose metabolism. Four genes (DPE2, SS2, TPS3, and SUS2) are marked in red. We identified the metabolism pathway using DAVID.

Table 3. Trehalose-6-phosphate synthase gene in rice samples.

\begin{tabular}{|c|c|c|c|c|}
\hline Genes & Gene Symbol & Gene Name & $\operatorname{logFC}$ & FDR \\
\hline \multicolumn{5}{|l|}{$\log F C<0$} \\
\hline Os11t0513900-01 & OsTPS8, OsTPS1, TPS1 & trehalose-6-phosphate synthase 1 & -1.589154 & 0.5285901 \\
\hline Os02t0790500-02 & OsTPS5 & trehalose-6-phosphate synthase 5 & -0.425324 & 0.08463762 \\
\hline Os11t0156600-00 & OsTPS8, OsTPS1, TPS1 & trehalose-6-phosphate synthase 1 & -0.3653828 & 0.9241036 \\
\hline Os08t0409100-01 & OsTPP6 & trehalose-6-phosphate phosphatase 6 & -0.141309 & 0.6490201 \\
\hline Os03t0372500-03 & OsTPP1, OsTPS & $\begin{array}{l}\text { trehalose-6-phosphate phosphatase } 1, \\
\text { trehalose 6-P synthase }\end{array}$ & -0.000663483 & 0.9997236 \\
\hline \multicolumn{5}{|l|}{$\log F C>0$} \\
\hline Os09t0332100-01 & OsTPP3 & trehalose-6-phosphate phosphatase 3 & 0.2046861 & 0.7819962 \\
\hline Os09t0369400-01 & OsTPP7 & trehalose-6-phosphate phosphatase 7 & 0.3268572 & 0.4806699 \\
\hline Os10t0553300-01 & OsTPP2 & trehalose-6-phosphate phosphatase 2 & 0.368067102 & 0.601752321 \\
\hline Os03t0386500-01 & OsTPP9 & trehalose-6-phosphate phosphatase 9 & 0.7412287 & 0.04455191 \\
\hline Os02t0753000-01 & OsTPP4 & trehalose-6-phosphate phosphatase 4 & 1.243797 & 0.318923 \\
\hline
\end{tabular}

\subsection{Verification of Differential Expression by Quantitative Real-Time PCR}

To validate expression profiles of genes in RNA sequencing results, we performed qRT-PCR for two trehalose-6-phosphate synthase (TPS) genes, OsTPS1 (Os11t0156600) and OsTPs5 (Os02t0790500), and four for trehalose-6-phosphate phosphatase (TPP) genes, OsTPP6 (Os08t0409100), OsTPP3 (Os09t0332100), OsTPP4 (Os02t0753000), and OsTPP9 (Os03t0386500). 
Expression levels of OsTPS1 and OsTPS5 genes were decreased in PsGAPDH-OX plants compared to those in the wild-type. Furthermore, the transcript levels of the TPP genes were significantly induced (Figure 8). Results of qRT-PCR correlated well with transcription levels estimated from RNA sequencing data, thus supporting the involvement of these genes in the defense against salinity stress in transgenic rice plants. Additionally, these results indicated that low levels of T6P and high levels of trehalose in PsGAPDH-OX rice plants might play a role in the resistance of transgenic plants against abiotic stress.
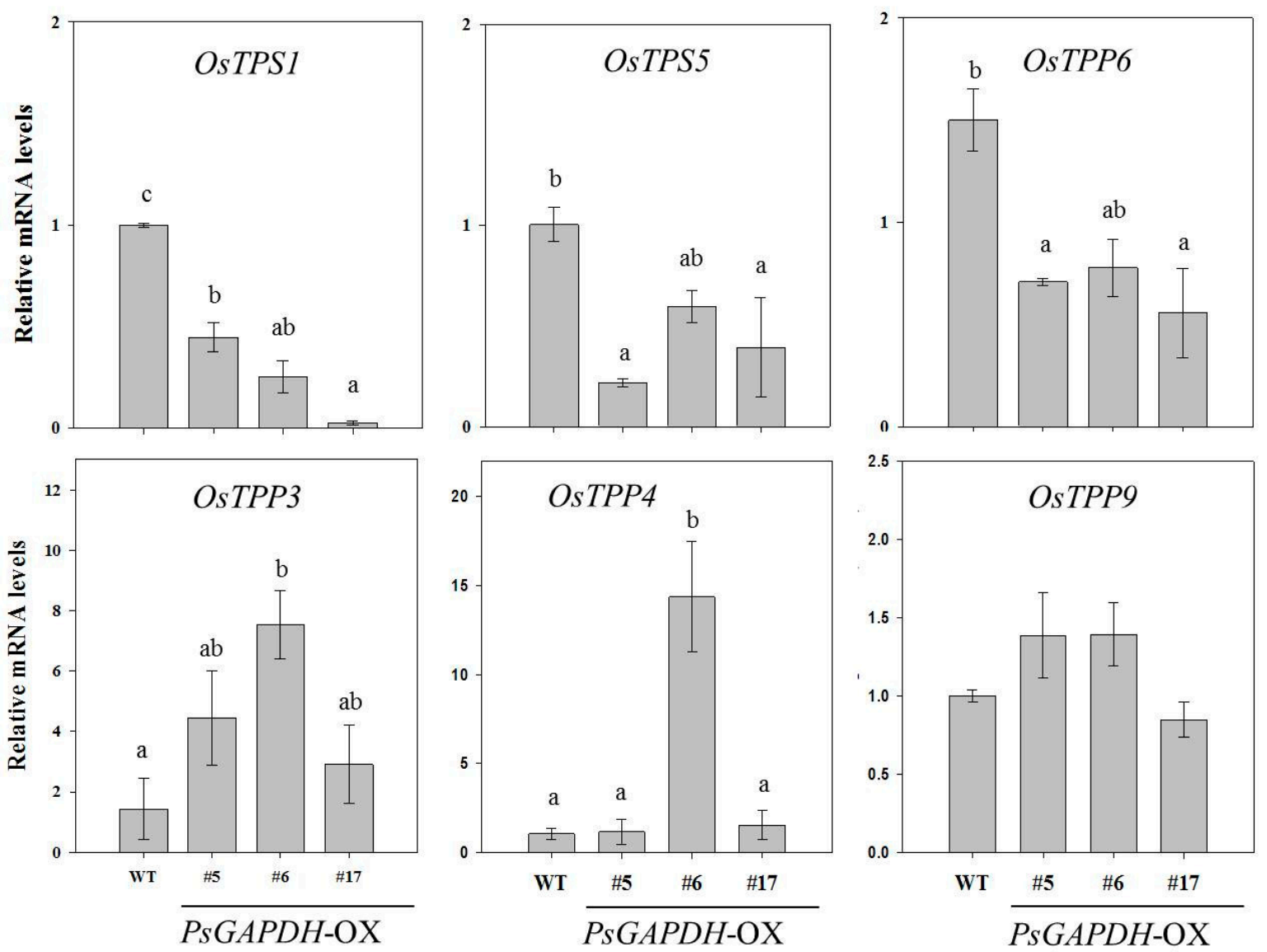

Figure 8. Expression levels of starch and sucrose-associated genes in wild-type and PsGAPDH-OX plants under NaCl stress conditions. Quantitative real-time PCR data were analyzed using the $2^{-\Delta \Delta C T}$ method with OsActin 1 gene as an internal control. Values are presented as means \pm SD of three independent measurements. Different lowercase letters indicate significant differences (ANOVA with Tukey's HSD, $p<0.05$ ).

\section{Discussion}

GAPDH genes are commonly used as internal controls for the relative quantitation of gene expression [40]. However, a recent study has revealed that GAPDH displays unacceptably high expression variability, thus limiting its use as an internal control [41]. Indeed, several GAPDH genes have been characterized in relation to abiotic stresses. In particular, transgenic rice plants overexpressing OsGAPC3 show significantly increased tolerance to salt stress, both during and after germination [40]. In the present study, we found that PsGAPDH-OX rice plants were more adaptive to salt stress than wild-type ones at germination and seedling growth stages (Figures 2 and 3). Especially, PsGAPDH-OX \#6 was the most tolerant against salt stress. This result suggests that GAPDH activity is required for the acclimation of rice plants to salt stress in the early growth stage. GAPDH is a highly conserved glycolytic enzyme that plays an important role in carbon metabolism pathways. Glycolysis is a principal metabolic pathway that provides precursors for biosynthetic reactions and takes part in the stress adaptation of plants [12-14]. Recent metabolomics 
analyses have demonstrated that long-term salt stress can alter cellular metabolic processes, including glycolysis, gluconeogenesis, and sucrose metabolism [13,40]. Plants can accumulate osmotic substances such as proline, trehalose, and sucrose to adapt to salt stress, because they can induce metabolic processes associated with osmolyte production $[13,40]$.

Our RNA sequencing analysis data indicated that overexpression of $P_{S} G A P D H$ caused transcriptomic changes for a considerable number of genes involved in various physiological processes of rice. Those genes found to be responsive to salt stress in rice plants overexpressing PSGAPDH in the present study have previously been reported to be involved in trehalose biosynthesis processes such as trehalose-6-phosphate synthase (TPS) and trehalose-6-phosphate phosphatase (TPP). Among various osmolytes, trehalose ( $\alpha$-D-glucopyranosyl- $\alpha$-D-glucopyranoside), a non-reducing disaccharide, is a principal compatible solute and a potential signal metabolite in plants. In plants, there is only one pathway for trehalose biosynthesis. It consists of a two-step process involving TPS and TPP that synthesize and subsequently dephosphorylate trehalose-6-phosphate (T6P) as an intermediate. Previous studies have shown that genetic modification of the TPS/TPP gene can increase stress resistance in different species [42,43]. Heterologous expression of bacterial or yeast trehalose biosynthesis gene in tobacco, Arabidopsis, rice, and potato can increase their stress tolerance [44]. Overexpression of OsTPP1 can improve the resistance to salt and cold. It can also trigger the expression of a series of abiotic response genes, thus increasing the stress tolerance of rice [45]. Previous studies have shown that some TPS/TPP genes are directly involved in stress tolerance by improving trehalose contents in several plants [46].

\section{Conclusions}

Our results suggest that the PSGAPDH gene might participate in salt tolerance through coordination with these responsive genes. Hence, we speculate that $P_{S} G A P D H$ is possibly involved in various cellular processes in addition to the metabolism of starch and sucrose. Taken together, our findings suggest that PsGAPDH plays an important role in the metabolism of starch and sucrose during the adaptation of plants to salt stress.

Supplementary Materials: The following are available online at https:/ / www.mdpi.com/article/10 .3390 / genes12050641/s1, Supplementary Table S1: The location of T-DNA insertions over the rice chromosomes; Supplementary Table S2: Raw data information; Supplementary Table S3: Alignment rate; Supplementary Table S4: Primers used in qRT-PCR for PsGAPDH and the validation of trehalose6-phosphate synthase genes.

Author Contributions: Conceptualization, H.L., H.H. and G.L.; methodology, T.K. and D.L.; investigation, H.L., S.K. (Soyoung Kim) and S.K. (Soorin Kim); data curation, H.L., H.C. and S.P.; writing-original draft preparation, H.L., T.K. and H.H.; writing—review and editing, H.J. and W.C.; project administration, G.L. All authors have read and agreed to the published version of the manuscript.

Funding: This work was supported by a grant from the Next Generation21 Program (Project No. PJ015782), Rural Development Administration, Republic of Korea and the Research Program of the National Marine Biodiversity Institute of Korea (MABIK2021M00600).

Institutional Review Board Statement: Not applicable.

Informed Consent Statement: Not applicable.

Data Availability Statement: Data is contained within the article or Supplementary Materials.

Conflicts of Interest: The authors declare no conflict of interest. 


\section{References}

1. Li, Y.; Xiao, J.; Chen, L.; Huang, X.; Cheng, Z.; Han, B.; Zhang, Q.; Wu, C. Rice Functional Genomics Research: Past Decade and Future. Mol. Plant 2018, 11, 359-380. [CrossRef]

2. Zhu, J.K. Plant salt tolerance. Trends Plant Sci. 2001, 6, 66-71. [CrossRef]

3. Schmidt, R.; Mieulet, D.; Hubberten, H.M.; Obata, T.; Hoefgen, R.; Fernie, A.R.; Fisahn, J.; San Segundo, B.; Guiderdoni, E.; Schippers, J.H.; et al. Salt-responsive ERF1 regulates reactive oxygen species-dependent signaling during the initial response to salt stress in rice. Plant Cell 2013, 25, 2115-2131. [CrossRef]

4. Ghosh, A.; Pareek, A.; Sopory, S.K.; Singla-Pareek, S.L. A glutathione responsive rice glyoxalase II, OsGLYII-2, functions in salinity adaptation by maintaining better photosynthesis efficiency and anti-oxidant pool. Plant J. 2014, 80, 93-105. [CrossRef]

5. Zhu, N.; Cheng, S.; Liu, X.; Du, H.; Dai, M.; Zhou, D.X.; Yang, W.; Zhao, Y. The R2R3-type MYB gene OsMYB91 has a function in coordinating plant growth and salt stress tolerance in rice. Plant Sci. 2015, 236, 146-156. [CrossRef]

6. Guo, L.; Ma, F.; Wei, F.; Fanella, B.; Allen, D.K.; Wang, X. Cytosolic phosphorylating glyceraldehyde-3-phosphate dehydrogenases affect Arabidopsis cellular metabolism and promote seed oil accumulation. Plant Cell 2014, 26, 3023-3035. [CrossRef] [PubMed]

7. Han, S.; Wang, Y.; Zheng, X.; Jia, Q.; Zhao, J.; Bai, F.; Hong, Y.; Liu, Y. Cytoplastic Glyceraldehyde-3-Phosphate Dehydrogenases Interact with ATG3 to Negatively Regulate Autophagy and Immunity in Nicotiana benthamiana. Plant Cell 2015, 27, 1316-1331. [CrossRef]

8. Kim, S.C.; Guo, L.; Wang, X. Nuclear moonlighting of cytosolic glyceraldehyde-3-phosphate dehydrogenase regulates Arabidopsis response to heat stress. Nat. Commun. 2020, 11, 3439. [CrossRef] [PubMed]

9. Zeng, L.; Deng, R.; Guo, Z.; Yang, S.; Deng, X. Genome-wide identification and characterization of Glyceraldehyde-3-phosphate dehydrogenase genes family in wheat (Triticum aestivum). BMC Genom. 2016, 17, 240. [CrossRef]

10. Piattoni, C.V.; Ferrero, D.M.L.; Dellaferrera, I.; Vegetti, A.; Iglesias, A.A. Cytosolic Glyceraldehyde-3-Phosphate Dehydrogenase Is Phosphorylated during Seed Development. Front. Plant Sci. 2017, 8, 522. [CrossRef]

11. Plaxton, W.C. The Organization and Regulation of Plant Glycolysis. Annu. Rev. Plant Physiol. Plant Mol. Biol. 1996, 47, 185-214. [CrossRef] [PubMed]

12. Rizhsky, L.; Liang, H.; Mittler, R. The combined effect of drought stress and heat shock on gene expression in tobacco. Plant Physiol. 2002, 130, 1143-1151. [CrossRef] [PubMed]

13. Kim, J.K.; Bamba, T.; Harada, K.; Fukusaki, E.; Kobayashi, A. Time-course metabolic profiling in Arabidopsis thaliana cell cultures after salt stress treatment. J. Exp. Bot. 2007, 58, 415-424. [CrossRef] [PubMed]

14. Zhang, J.; Zhang, Y.; Du, Y.; Chen, S.; Tang, H. Dynamic metabonomic responses of tobacco (Nicotiana tabacum) plants to salt stress. J. Proteome Res. 2011, 10, 1904-1914. [CrossRef]

15. Redkar, R.J.; Lemke, P.A.; Singh, N.K. Altered gene expression in Aspergillus nidulans in response to salt stress. Mycologia 1996, 88, 256-263. [CrossRef]

16. Jeong, M.J.; Park, S.C.; Kwon, H.B.; Byun, M.O. Isolation and characterization of the gene encoding glyceraldehyde-3-phosphate dehydrogenase. Biochem. Biophys. Res. Commun. 2000, 278, 192-196. [CrossRef] [PubMed]

17. Jeong, M.J.; Park, S.C.; Byun, M.O. Improvement of salt tolerance in transgenic potato plants by glyceraldehyde-3 phosphate dehydrogenase gene transfer. Mol. Cells 2001, 12, 185-189. [PubMed]

18. Dubouzet, J.G.; Sakuma, Y.; Ito, Y.; Kasuga, M.; Dubouzet, E.G.; Miura, S.; Seki, M.; Shinozaki, K.; Yamaguchi-Shinozaki, K. OsDREB genes in rice, Oryza sativa L., encode transcription activators that function in drought-, high-salt- and cold-responsive gene expression. Plant J. 2003, 33, 751-763. [CrossRef]

19. Lim, H.; Hwang, H.J.; Kim, A.R.; Cho, M.H.; Ji, H.S.; Kim, C.K.; Ji, S.U.; Cho, J.I.; Park, S.C.; Lee, G.S. A simple, rapid and systematic method for the developed GM rice analysis. Plant Biotechnol. Rep. 2016, 10, 25-33. [CrossRef]

20. Schuster, S.C. Next-generation sequencing transforms today's biology. Nat. Methods 2008, 5, 16-18. [CrossRef]

21. Mardis, E.R. The impact of next-generation sequencing technology on genetics. Trends Genet. 2008, 24, 133-141. [CrossRef] [PubMed]

22. Wang, Z.; Gerstein, M.; Snyder, M. RNA-Seq: A revolutionary tool for transcriptomics. Nat. Rev. Genet. 2009, 10, 57-63. [CrossRef]

23. Hoen, P.A.; Friedlander, M.R.; Almlof, J.; Sammeth, M.; Pulyakhina, I.; Anvar, S.Y.; Laros, J.F.; Buermans, H.P.; Karlberg, O.; Brannvall, M.; et al. Reproducibility of high-throughput mRNA and small RNA sequencing across laboratories. Nat. Biotechnol. 2013, 31, 1015-1022. [CrossRef]

24. Kakumanu, A.; Ambavaram, M.M.; Klumas, C.; Krishnan, A.; Batlang, U.; Myers, E.; Grene, R.; Pereira, A. Effects of drought on gene expression in maize reproductive and leaf meristem tissue revealed by RNA-Seq. Plant Physiol. 2012, 160, 846-867. [CrossRef] [PubMed]

25. Koenig, D.; Jimenez-Gomez, J.M.; Kimura, S.; Fulop, D.; Chitwood, D.H.; Headland, L.R.; Kumar, R.; Covington, M.F.; Devisetty, U.K.; Tat, A.V.; et al. Comparative transcriptomics reveals patterns of selection in domesticated and wild tomato. Proc. Natl. Acad. Sci. USA 2013, 110, E2655-E2662. [CrossRef]

26. Zhang, T.; Zhao, X.; Wang, W.; Huang, L.; Liu, X.; Zong, Y.; Zhu, L.; Yang, D.; Fu, B.; Li, Z. Deep transcriptome sequencing of rhizome and aerial-shoot in Sorghum propinquum. Plant Mol. Biol. 2014, 84, 315-327. [CrossRef]

27. Liao, J.L.; Zhou, H.W.; Peng, Q.; Zhong, P.A.; Zhang, H.Y.; He, C.; Huang, Y.J. Transcriptome changes in rice (Oryza sativa L.) in response to high night temperature stress at the early milky stage. BMC Genom. 2015, 16, 18. [CrossRef] 
28. Shi, C.Y.; Yang, H.; Wei, C.L.; Yu, O.; Zhang, Z.Z.; Jiang, C.J.; Sun, J.; Li, Y.Y.; Chen, Q.; Xia, T.; et al. Deep sequencing of the Camellia sinensis transcriptome revealed candidate genes for major metabolic pathways of tea-specific compounds. BMC Genom. 2011, 12, 131. [CrossRef]

29. Li, H.W.; Zang, B.S.; Deng, X.W.; Wang, X.P. Overexpression of the trehalose-6-phosphate synthase gene OsTPS1 enhances abiotic stress tolerance in rice. Planta 2011, 234, 1007-1018. [CrossRef]

30. Fuse, T.; Sasaki, T.; Yano, M. Ti-plasmid vectors useful for functional analysis of rice genes. Plant Biotechnol. Rep. 2001, 18, 219-222. [CrossRef]

31. Toki, S.; Hara, N.; Ono, K.; Onodera, H.; Tagiri, A.; Oka, S.; Tanaka, H. Early infection of scutellum tissue with Agrobacterium allows high-speed transformation of rice. Plant J. 2006, 47, 969-976. [CrossRef]

32. Yoo, S.D.; Cho, Y.H.; Sheen, J. Arabidopsis mesophyll protoplasts: A versatile cell system for transient gene expression analysis. Nat. Protoc. 2007, 2, 1565-1572. [CrossRef] [PubMed]

33. Duan, J.; Cai, W. OsLEA3-2, an abiotic stress induced gene of rice plays a key role in salt and drought tolerance. PLoS ONE 2012, 7, e45117. [CrossRef]

34. Bolger, A.M.; Lohse, M.; Usadel, B. Trimmomatic: A flexible trimmer for Illumina sequence data. Bioinformatics 2014, 30, 2114-2120. [CrossRef]

35. Kim, D.; Langmead, B.; Salzberg, S.L. HISAT: A fast spliced aligner with low memory requirements. Nat. Methods 2015, 12, 357-360. [CrossRef] [PubMed]

36. Liao, Y.; Smyth, G.K.; Shi, W. featureCounts: An efficient general purpose program for assigning sequence reads to genomic features. Bioinformatics 2014, 30, 923-930. [CrossRef] [PubMed]

37. Robinson, M.D.; McCarthy, D.J.; Smyth, G.K. edgeR: A Bioconductor package for differential expression analysis of digital gene expression data. Bioinformatics 2010, 26, 139-140. [CrossRef]

38. Zhou, X.; Lindsay, H.; Robinson, M.D. Robustly detecting differential expression in RNA sequencing data using observation weights. Nucleic Acids Res. 2014, 42, e91. [CrossRef]

39. Huang, D.W.; Sherman, B.T.; Tan, Q.; Collins, J.R.; Alvord, W.G.; Roayaei, J.; Stephens, R.; Baseler, M.W.; Lane, H.C.; Lempicki, R.A. The DAVID Gene Functional Classification Tool: A novel biological module-centric algorithm to functionally analyze large gene lists. Genome Biol. 2007, 8, R183. [CrossRef]

40. Zhang, X.H.; Rao, X.L.; Shi, H.T.; Li, R.J.; Lu, Y.T. Overexpression of a cytosolic glyceraldehyde-3-phosphate dehydrogenase gene OsGAPC3 confers salt tolerance in rice. Plant Cell Tissue Organ Cult. 2011, 107, 1-11. [CrossRef]

41. Jain, M.; Nijhawan, A.; Tyagi, A.K.; Khurana, J.P. Validation of housekeeping genes as internal control for studying gene expression in rice by quantitative real-time PCR. Biochem. Biophys. Res. Commun. 2006, 345, 646-651. [CrossRef] [PubMed]

42. Lyu, J.I.; Min, S.R.; Lee, J.H.; Lim, Y.H.; Kim, J.K.; Bae, C.H.; Liu, J. Overexpression of a trehalose-6-phosphate synthase/phosphatase fusion gene enhances tolerance and photosynthesis during drought and salt stress without growth aberrations in tomato. Plant Cell Tissue Organ Cult. 2013, 112, 257-262. [CrossRef]

43. Miranda, J.A.; Avonce, N.; Suarez, R.; Thevelein, J.M.; Van Dijck, P.; Iturriaga, G. A bifunctional TPS-TPP enzyme from yeast confers tolerance to multiple and extreme abiotic-stress conditions in transgenic Arabidopsis. Planta 2007, 226, 1411-1421. [CrossRef]

44. Hohmann, S.; Bell, W.; Neves, M.J.; Valckx, D.; Thevelein, J.M. Evidence for trehalose-6-phosphate-dependent and -independent mechanisms in the control of sugar influx into yeast glycolysis. Mol. Microbiol. 1996, 20, 981-991. [CrossRef]

45. Ge, L.F.; Chao, D.Y.; Shi, M.; Zhu, M.Z.; Gao, J.P.; Lin, H.X. Overexpression of the trehalose-6-phosphate phosphatase gene OsTPP1 confers stress tolerance in rice and results in the activation of stress responsive genes. Planta 2008, 228, 191-201. [CrossRef]

46. Avonce, N.; Leyman, B.; Mascorro-Gallardo, J.O.; Van Dijck, P.; Thevelein, J.M.; Iturriaga, G. The Arabidopsis trehalose-6-P synthase AtTPS1 gene is a regulator of glucose, abscisic acid, and stress signaling. Plant Physiol. 2004, 136, 3649-3659. [CrossRef] 